\section{Diese Regeln für Veranstaltungen beachten}

Veranstaltungen mit Eventcharakter für Geschäftsfreunde, Kunden und natürlich die eigenen Angestellten sind immer dann abzugsfähig, wenn weder Aufwendungen für unübliche Bewirtungen noch für ein unangemessenes Unterhaltungsprogramm angefallen sind. Auch der Ort der Veranstaltung und/oder die Art und Weise der Unterhaltung der Gäste sollte nicht aus dem Rahmen fallen.

\section{Feiern mit persönlichem Bezug}

Auch Feiern mit persönlichem Bezug sind nicht unbedingt vom Steuerabzug ausgeschlossen. So hat der BFH in der letzten Zeit mehrfach entschieden. Ob Examen, der Einstand, das Dienstjubiläum oder der Abschied, all das sind Feiern, die im Wesentlichen beruflich motiviert sind. Es kommt dann auf die Zusammensetzung der Gästeliste (überwiegend berufliche Kontakte oder Angehörige des öffentlichen Lebens) an und welchen Charakter das Fest hat, ob die Kosten steuerlich absetzbar sind. Geburtstagsfeiern sind an sich nicht beruflich motiviert. Doch auch diese Feiern können als Betriebsausgaben absetzbar sein. Voraussetzung: Es werden nahezu ausschließlich Geschäftsfreunde, Kunden oder Arbeitskollegen eingeladen. Wenn dann die Feier noch in den beruflichen Räumlichkeiten stattfindet, steht der Absetzbarkeit eigentlich nichts entgegen.

\section{Auf die Dokumentation kommt es an}

Will man die steuerliche Absetzbarkeit erreichen, so müssen die Umstände der Feier akribisch dokumentiert werden. Die aufbewahrte Einladung und die Aufzeichnung der eingeladenen Gäste sollten den Kostenbelegen direkt beigefügt werden. So gibt es später keine Probleme mit dem Finanzamt.

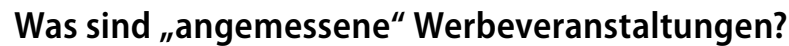

Der BFH beurteilte die Gartenfeste jedoch anders (Urteil vom 13. Juli 2016, Az. 16 VIII R 26/14): Die Veranstaltung war nach Ansicht des höchsten deutschen Finanzgerichts in Bezug auf die Kosten und die Durchführung weder außergewöhnlich, noch lag eine überflüssige und unangemessene Unterhaltung und Repräsentation vor. Auch die große Gästezahl an sich und der private Garten als Veranstaltungsort seien nicht schädlich. Die bloße Annahme eines „Eventcharakters“ alleine reiche nicht aus, da die unter das Abzugsverbot fallenden Aufwendungen für „ähnliche Zwecke“ wie bei den Regelbeispielen „unüblich“ sein müssen. Dies kann aufgrund eines besonderen Ortes der Veranstaltung oder der Art und Weise der Unterhaltung der Gäste der Fall sein.

Nun muss das Finanzgericht erneut prüfen, ob die Art und Durchführung der „Herrenabende“ den Schluss zulässt, dass diese sich von "gewöhnlichen Gartenfesten“ abheben und mit der Einladung zu einer Segelregatta oder Jagdgesellschaft vergleichbar sind.

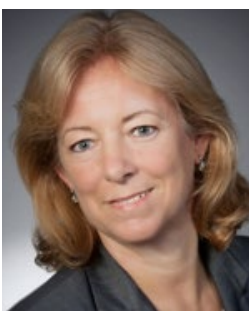

Gabriela Scholz STB/WP

Sankt Augustin

www.scholz-steuer.de

\section{Hier steht eine Anzeige.}

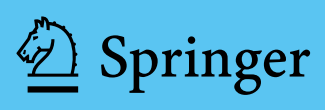

